\title{
Leucine Zipper-EF-Hand Containing Transmembrane Protein I Is a Potential Prognostic Biomarker and Promotes Cell Progression in Prostate Cancer
}

This article was published in the following Dove Press journal: Cancer Management and Research

\author{
Lihua Piao' \\ Haoyue $\mathrm{Li}^{1,2}$ \\ Ying Feng ${ }^{1,2}$ \\ Xiaogang $\mathrm{Li}^{3}$ \\ Yan Cui ${ }^{4}$ \\ Yanhua Xuan ${ }^{1,2}$ \\ 'Institute for Regenerative Medicine, \\ Yanbian University College of Medicine, \\ Yanji I33002, Jilin Province, People's \\ Republic of China; ${ }^{2}$ Department of \\ Pathology, Yanbian University College of \\ Medicine, Yanji 133002, Jilin Province, \\ People's Republic of China; ${ }^{3}$ Department \\ of Urology, Yanbian University Affiliated \\ Hospital, Yanji I33002, Jilin Province, \\ People's Republic of China; ${ }^{4}$ Department \\ of Oncology, Yanbian University Affiliated \\ Hospital, Yanji 133002, Jilin Province, \\ People's Republic of China
}

Purpose: The leucine zipper-EF-hand containing transmembrane protein 1 (LETM1) is a mitochondrial protein that has been associated with the occurrence and development of malignant tumors. Previous studies have shown that LETM1 expression is increased in several types of human cancer and is associated with a poor clinical outcome. However, the role of LETM1 in prostate cancer (PCa) has not yet been determined. In this study, we investigated the clinicopathological significance of LETM1 expression and its role in PCa progression.

Methods: We assessed the expression of LETM1 and genes related to cancer stemness, epithelial-mesenchymal transition (EMT), cell cycle, and PI3K/Akt signaling in 133 paraffinembedded PCa tissue samples and cancer cells by using immunohistochemistry, immunofluorescence, and Western blotting.

Results: LETM1 expression was significantly increased in $\mathrm{PCa}$, and it was positively correlated with Gleason score, pathologic tumor (pT) stage, clinical stage, and high microvessel density. Survival analysis showed that patients with PCa with a high level of LETM1 expression exhibited a low overall survival. Cox regression analysis indicated that LETM1 is an independent poor prognostic PCa factor. Additionally, the expression of LETM1 was correlated with cancer cell stemness-associated genes, EMT-related genes, cell cycle regulatory genes, and PI3K/Akt signaling gene expression in PCa. Furthermore, knocking down LETM1 expression down-regulated the expression of stemness-related proteins, while inhibiting tumor spheroid formation, EMT-like changes, cell proliferation, migration, and invasion in PCa cells. Importantly, the PI3K inhibitor LY294002 strongly inhibited the expression of LETM1, pPI3K-p85, and pAkt (Thr308, Ser473) in PCa cells.

Conclusion: These results indicate that LETM1 expression is associated with cancer cell stemness, promotes EMT-like changes and cell proliferation and is a potential prognostic biomarker for PCa.

Keywords: prostate cancer, leucine zipper-EF-hand containing transmembrane protein 1, epithelial-mesenchymal transition, prognosis

\section{Introduction}

Prostate cancer ( $\mathrm{PCa})$ is the second most prevalent cancer in men worldwide, accounting for an estimated 26,730 deaths in 2016. ${ }^{1,2}$ Metastasis is a high-risk complication and the major cause of death in patients with $\mathrm{PCa}^{3,4}$ Androgen deprivation therapy remains the primary clinical treatment for patients in the early stages of PCa. As the disease develops into castration-resistant PCa, almost all patients with advanced PCa will experience recurrence and distal organ metastasis. ${ }^{5}$ Therefore, it is necessary to improve

Yan Cui

Department of Oncology, Yanbian University Affiliated Hospital, No. 977,

Gongyuan Road, Yanji City 133002 ,

People's Republic of China

Tel +86-433-2435107

Fax +86-433-2732456

Email cuiyan2005@hotmail.com 
current therapeutic strategies and explore new molecular biomarkers for predicting the progression of $\mathrm{PCa}$ and for developing targeted therapies.

Cancer stem-like cells (CSCs) are a subpopulation of tumor cells with tumorigenic and metastatic capacities. ${ }^{6-8}$ Previous studies have shown that the proportion of stem cells present in tumors is closely related to disease progression. A high CSC count is associated with poor clinical outcome and metastasis. ${ }^{9}$ Several studies have confirmed that epithelial-mesenchymal transition (EMT) is associated with the emergence of drug resistance and acquisition of CSC-like properties. ${ }^{10,11}$ Inducing EMT creates a self-renewing state that enables redifferentiation to allow colonization and growth at distant metastatic sites. ${ }^{12,13}$ Many signals from the tumor microenvironment contribute to the induction of EMT and development prostate CSC phenotypes that, in turn, initiate a cascade of signals leading to metastasis. ${ }^{12}$ Conventional therapies have failed to eradicate carcinoma cells that have entered a CSC-like state via activation of EMT. ${ }^{14}$

Leucine zipper-EF-hand containing transmembrane protein 1 (LETM1) is a mitochondrial inner membrane protein that is conserved in eukaryotes from yeast to humans. ${ }^{15,16}$ The LETM1 gene was first identified in Wolf-Hirschhorn syndrome and encodes the human homolog of the yeast Mdm38p gene. ${ }^{17}$ LETM1-mediated mitochondrial biogenesis increases the glycolytic ATP supply, and the mitochondrial dynamics regulate stem cell fate. ${ }^{18,19}$ LETM1 is a biomarker associated with poor prognosis and tumor progression in patients with colorectal adenocarcinoma as well as breast, bladder, thyroid, and esophageal cancers. ${ }^{20-24}$ However, the clinical significance of LETM1, its function in tumorigenesis, and its regulation in $\mathrm{PCa}$ are not yet fully understood.

In this study, we investigated the clinical significance of LETM1 in PCa and evaluated the relationship between its expression and cancer stemness, cell proliferation, EMT-related genes, and the PI3K/Akt pathway.

\section{Materials and Methods}

\section{Tissue Specimens}

A total of 133 cases of PCa tissue samples and 14 cases of benign prostatic hyperplasia (BPH) tissue samples were obtained from patients who underwent prostate surgery and were stored in Xi'an Alena Biotechnology Ltd., Co. (Outdo Biotech) and Department of Pathology of Yanbian University Affiliate Hospital. No patient received preoperative chemotherapy or radiotherapy. Pathological parameters, including age, tumor grade, clinical stage, primary tumor (pT) stage, and lymph node metastasis were carefully reviewed in all prostate cancer patients. The written informed consent was obtained from each patient, and that their privacy would be maintained. This study was approved by the Human Ethics Committee and the Research Ethics Committee of Yanbian University, and conducted in accordance with the Declaration of Helsinki (No. YBUCM-81760531).

\section{Cell Lines}

LNCaP, PC3 and DU145 cell lines (purchased from American-Type Culture Collection, Manassas, USA) were maintained in RPMI-1640 with $10 \%$ heat-inactivated fetal bovine serum (FBS, Life Technologies, Grand Island, NY), $100 \mathrm{mg} / \mathrm{mL}$ penicillin $\mathrm{G}$, and $50 \mathrm{mg} / \mathrm{mL}$ streptomycin (Life Technologies, Grand Island, NY) at $37^{\circ} \mathrm{C}$ in a humidified atmosphere containing 5\% CO2. Cells were treated (for $48 \mathrm{~h}$ unless otherwise specified) with LY24002 (Abcam, Cambridge, UK) according to the manufacturer's instructions.

\section{Immunohistochemical (IHC) Analysis}

Tissue sections on microscope slides were deparaffinized, hydrated, and treated with $3 \% \mathrm{H}_{2} \mathrm{O}_{2}$ for 15 min to quench endogenous peroxidase activity. Sections were immersed in TE buffer (10 mM Tris and $1 \mathrm{mM}$ EDTA, $\mathrm{pH}$ 9.3) for epitope retrieval in a microwave for $30 \mathrm{~min}$. The slides were then incubated with $4 \%$ bovine serum albumin for 30 min to block nonspecific immunoreactivity. The sections were then incubated with primary antibodies for $60 \mathrm{~min}$ at room temperature. Antibodies used in present study were listed in Supplementary Table 1. Sections were then incubated with an anti mouse/rabbit antibody (Envision plus, Dako, Denmark, catalog: K801021-2) for $30 \mathrm{~min}$ at room temperature. The chromogen used was ImmPACT AEC Peroxidase Substrate (VECTOR Laboratories) for 20 mins. After reading and taking photographs of the slides, sections were then stripped one time used stripping buffer (20\% SDS, $0.5 \mathrm{M}$ Tris, and mercaptoethanol) to removing the original antibody for one hour in a water bath at $56^{\circ} \mathrm{C}$ to remove the original antibody and then for 10 mins in alcohol so that the sections could be restained. Omitting the primary antibody provided negative controls for immunostaining. All the primary antibody stained in the same blots, and in serial sections.

The double immunostaining procedure was performed using a two-step method with LETM1 antibody and antiCD105 antibody (1:250, Abcam, Cambridge, UK, 
ab170943) to observe the relationship between the expression of LETM1 and microvessel density (MVD) in PCa. Primarily, for the LETM1 protocols, except that the chromogen with the 3, 3'-diaminobenzidine (Dako) for 10 mins (FLEX20), all steps are the same. Then, subsequent staining of the same section was performed after incubating the samples with an antibody to CD105 by ImmPACT AEC Peroxidase Substrate for 20 mins.

\section{Evaluation of the IHC Analysis}

Two pathologists (LHP \& YHX) who did not possess knowledge of the clinical data examined and scored all tissue specimens. IHC scores was measured, as follows: [IHC score 1], weak staining in $<50 \%$ or moderate staining in $<20 \%$ of carcinoma cells; [IHC score 2], weak staining in $\geqq 50 \%$, moderate staining in $20-50 \%$ or strong staining in $<20 \%$ of carcinoma cells; [IHC score 3], moderate staining in $\geqq 50 \%$ or strong staining in $\geqq 20 \%$ of carcinoma cells. Cases with score 2 and 3 were regarded as positivity for each protein expression, the staining results were semiquantitatively scored as negative and positive. In case of discrepancies, a final score was established by reassessment by both pathologists using a double-headed microscope. ${ }^{25}$

\section{Western Blotting}

Immuno-blot analysis was performed as previously described. ${ }^{4}$ Cells were collected and lysed with protease inhibitors. Equal amounts of proteins was loaded on SDSPAGE gels and then transferred to a PVDF membrane. Membranes were blocked $2 \mathrm{~h}$ at RT with 5\% skim milk (diluted in TBS), and then incubated with primary antibodies at $4{ }^{\circ} \mathrm{C}$ shaking for overnight. Membranes were then washed three times with TBST followed by incubation with horseradish peroxidase conjugated goat antirabbit/mouse IgG secondary antibody (1:500, BIOSS, Beijing, China) for $1 \mathrm{~h}$ at room temperature. Finally, the membranes were washed three times with TBST, and the protein bands were detected using an ECL system (Merck) according to the manufacturer's instructions.

\section{Immunofluorescence (IF) Analysis}

PC3 and DU145 cells were subcultured in a 6-well plate and incubated at $37{ }^{\circ} \mathrm{C} 5 \% \mathrm{CO}_{2}$. After sample preparation by fixation, permeabilization, and blocking, the slides were incubated with primary antibody diluted in $3 \%$ BSA at $56^{\circ}$ $\mathrm{C}$ overnight. Following primary antibody incubation, the slides were then washed three times and incubated with conjugated secondary antibodies in 3\% BSA for $1 \mathrm{~h}$ at RT.
The slides were washed three times with PBST. The cells were counter stained with DAPI (Vector Laboratorise, Burlingame, CA, USA). Finally, the location of proteins in cell were observed in a confocal laser scanning microscope (Carl Zeiss, Thornwood, New York). ${ }^{26}$

\section{Cell Transfection}

LETM1 endoribonuclease-prepared short interfering RNAs (esiRNA) was designed and synthesized by SigmaAldrich (St. Louis, MO, USA). The sequence of LETM1 esiRNA was listed in Supplementary Table 2. Additionally, control esiRNA (control) was also used in this study. Transfections were performed using Lipofectamine 2000 (Invitrogen, Life Technologies, Grand Island, NY) according to the manufacturer's instructions.

\section{Tumor Sphere-Forming Assay}

The PC3 and DU145 cells treated with or without LETM1 esiRNA for $48 \mathrm{~h}$ were seeded in Corning ultra-low attachment 6-well plates in $2 \mathrm{~mL}$ of DMEM/F12 medium supplemented with $10 \mathrm{ng} / \mathrm{mL}$ each of human bFGF and human EGF and with 2\% B27. After one week and two weeks, cell morphology was examined under light microscopy.

\section{Migration and Invasion Assays}

We used 24-well culture plate with an 8.0- $\mu \mathrm{m}$ transparent PET membrane separating the upper and lower halves of each well (Corning) to measure the migration ability and invasiveness of cells. For the invasion assay, we covered the upper side of the membrane with Matrigel (BD). The assays and counting of migrating or invading PC3 and DU145 cells were performed as described previously.26

\section{Cell Cycle Experiment}

We treated PC 3 and DU145 with 200 pM LETM1 esiRNA for $48 \mathrm{~h}$. Next, the cells were reseeded in new six-well plates and cultured. Then, the cells were fixed in $70 \%$ ethanol for $24 \mathrm{~h}$ at $4^{\circ} \mathrm{C}$. Thereafter, the cells were washed with PBS, and then stained them with $10 \mu \mathrm{g} / \mathrm{mL}$ propidium iodide solution for 30 min. We analyzed the cell cycle profiled by flow cytometry.

\section{Statistical Analysis}

Correlations were examined using Pearson's chi-square test as appropriate. Overall survival (OS) were determined using the Kaplan-Meier method and were compared using the Log rank test. The Cox proportional hazards model was used for multivariate analysis. The data are expressed as the mean \pm standard deviation (SD). Comparisons between groups were 
analyzed using Student's $t$-test. The statistical analysis was performed using SPSS 25.0 IBM Singapore Pte Ltd. (registration N 1975-01566-C) and GraphPad Prism 7.0 (GraphPad Software, Inc., La Jolla, CA, USA). All tests were two sided, and $\mathrm{P}<0.05$ was considered significant.

\section{Results}

\section{LETMI Expression is Associated with Unfavorable Clinicopathological Features and Poor Prognosis in $\mathrm{PCa}$}

The expression of LETM1 in specimens from 14 cases of BPH and 133 cases of PCa was determined through IHC analysis. Our results showed that 3 out of 14 BPH cases (21.4\%) and 95 out of 133 PCa cases (71.4\%) positively stained for LETM1 (Figure 1A-D and Supplementary Table 3). LETM1 expression was mainly detected in the cytoplasm of prostate epithelial cells (Figure 1A-D). Chi-square analysis showed that high LETM1 expression was significantly associated with Gleason score $(P=0.001)$, pT stage $(P=0.005)$, and clinical stage $(P=$ 0.006) (Table 1). CD105 (endoglin) was used as an endothelial cell marker, and its expression was observed in the new capillary blood vessels around cancer cells. Double IHC staining for LETM1 and CD105 in PCa tissues showed that microvessel density (MVD) was higher in LETM1-positive cases $(67.68 \pm 11.245)$ than in LETM1-negative cases $(54.35$ $\pm 10.291, P=0.042$ ) (Figure $1 \mathrm{E}-\mathrm{G}$ ). These results indicated that LETM1 expression might contribute to angiogenesis and tumor progression in $\mathrm{PCa}$.

To assess the association between LETM1 expression and the survival of patients with PCa, Kaplan-Meier curves with a Log rank test were used to determine the overall survival (OS). The expression of LETM1 was significantly associated with poor OS in patients with PCa $(P<0.001)$ (Figure 1H). Furthermore, univariate and multivariate Cox regression analyses demonstrated that lymph node metastasis (both $P<0.001$ ) and LETM1 expression in PCa $(P<0.001$ and $\mathrm{P}=0.006$, respectively) were significant poor prognostic factors of OS. (Supplementary Table 4). These results indicated that LETM1 expression is a potential biomarker for poor PCa prognosis.

\section{LETMI Expression Is Associated with Cancer Stemness in PCa}

We examined the protein levels of LETM1 and stemnessrelated proteins in PCa cell lines using Western blotting. PC3 and DU145 cell lines have higher metastatic potential
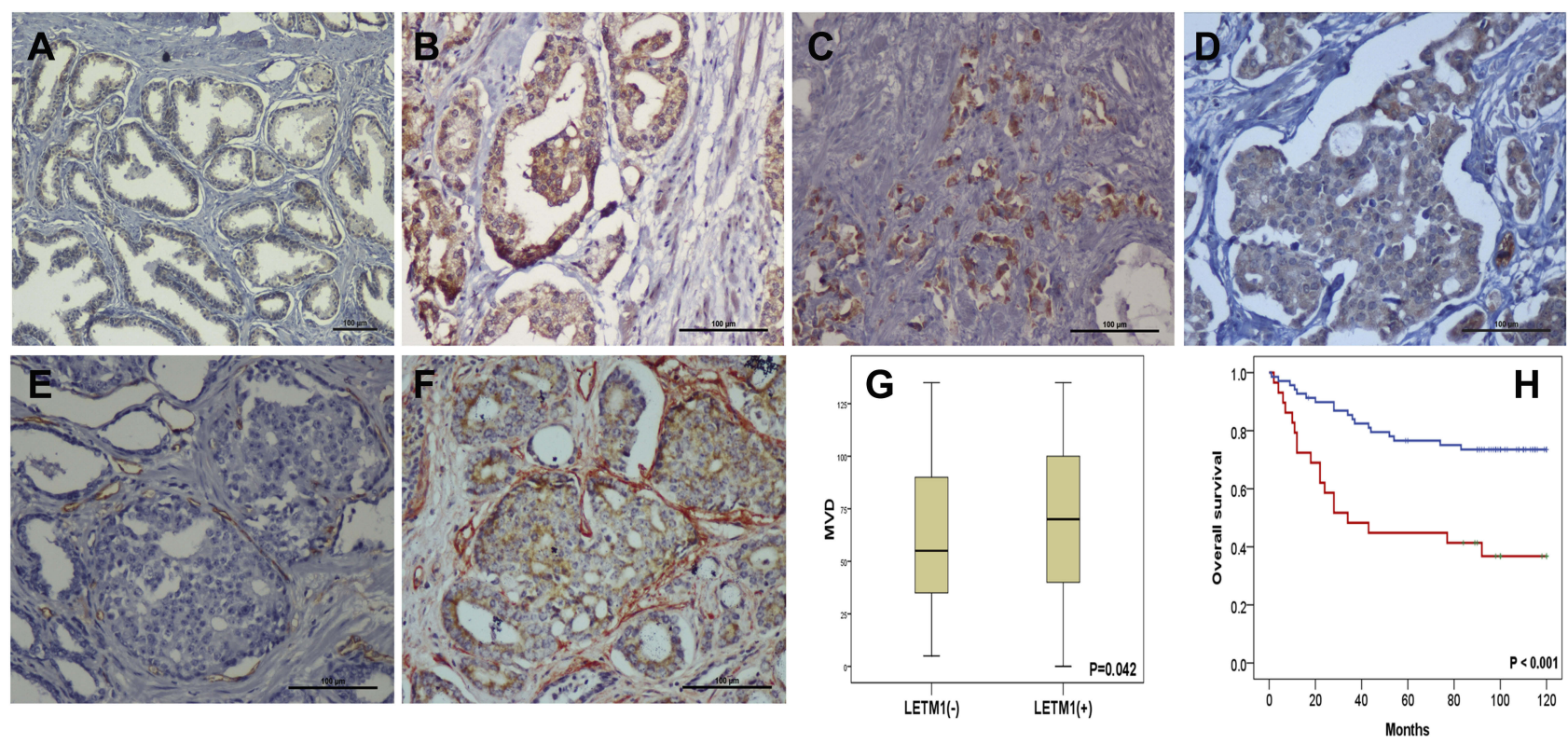

Figure I LETMI expression is associated with poor outcome in prostate cancer (PCa). Tissue Microarray (TMA) analysis immunohistochemistry staining of LETMI was performed to investigate LETMI expression in human PCa tissues; 133 cases of formalin-fixed primary PCa tissues and I4 benign prostatic hyperplasia (BPH) tissue samples were investigated. (A) Immunohistochemical analysis of LETMI expression in BPH. (B) LETMI expression in highly differentiated PCa tissues. (C) LETMI expression in poorly differentiated PCa tissues. (D) LETMI expression in lymphatic invasion PCa (original magnification 200x). Tumor angiogenesis is a key factor for LETMI in promoting tumor progression. CDI05 staining in LETMI-negative (E) and -positive (F) PCa samples. LETMI (brown reaction product) in the cancer cell cytoplasm, and CDI05 (red reaction product) in vascular endothelium (original magnification 200x). (G) Expression of LETMI in PCa was significantly associated with increased MVD. (H) Kaplan-Meier analysis was used to test for a significant association between LETMI expression and overall survival (OS) in PCa patients. Two types of OS outcomes were compared in the plot: a LETMI-positive group (red solid line) and a LETMI-negative group (blue solid line). The OS time in months is indicated on the $x$-axis, and the $y$-axis shows the probability of OS. 
Table I Comparison of Clinicopathologic Characteristics According to LETMI Expression in Prostate Cancer

\begin{tabular}{|c|c|c|c|c|c|c|}
\hline Variable & $n$ & $\begin{array}{l}\text { LETMI } \\
(-) \\
n(\%)\end{array}$ & $\begin{array}{l}\text { LETMI } \\
(+) \\
\mathrm{n}(\%)\end{array}$ & $\chi^{2}$ & $\mathbf{R}$ & $\mathbf{P}$ \\
\hline $\begin{array}{l}\text { Age (years) } \\
\qquad 65 \\
>65\end{array}$ & $\begin{array}{l}52 \\
81\end{array}$ & $\begin{array}{l}18(34.6) \\
20(24.7)\end{array}$ & $\begin{array}{l}34(65.4) \\
61(75.3)\end{array}$ & 1.266 & 0.092 & 0.260 \\
\hline $\begin{array}{l}\text { Gleason } \\
\text { Gleason4-6 } \\
\text { Gleason7-8 } \\
\text { Gleason9-10 }\end{array}$ & $\begin{array}{l}10 \\
101 \\
22\end{array}$ & $\begin{array}{l}8(80.0) \\
25(24.8) \\
5(22.7)\end{array}$ & $\begin{array}{l}2(20.0) \\
76(75.2) \\
17(77.3)\end{array}$ & 13.849 & 0.216 & 0.001 \\
\hline $\begin{array}{l}\text { PT stage } \\
\text { TI } \\
\text { T2 } \\
\text { T3 } \\
\text { T4 }\end{array}$ & $\begin{array}{l}55 \\
36 \\
31 \\
11\end{array}$ & $\begin{array}{l}24(43.6) \\
8(22.2) \\
5(16.1) \\
1(9.1)\end{array}$ & $\begin{array}{l}31(56.4) \\
28(77.8) \\
26(83.9) \\
10(90.9)\end{array}$ & 7.809 & 0.243 & 0.005 \\
\hline $\begin{array}{l}\text { Lymph node } \\
\text { metastasis } \\
\text { Negative } \\
\text { Positive }\end{array}$ & $\begin{array}{l}123 \\
10\end{array}$ & $\begin{array}{l}36(29.3) \\
2(20.0)\end{array}$ & $\begin{array}{l}87(70.7) \\
8(80.0)\end{array}$ & 0.203 & 0.039 & 0.652 \\
\hline $\begin{array}{l}\text { Clinical stage } \\
\text { I } \\
\text { II } \\
\text { III } \\
\text { IV }\end{array}$ & $\begin{array}{l}52 \\
38 \\
30 \\
13\end{array}$ & $\begin{array}{l}23(44.2) \\
9(23.7) \\
5(16.7) \\
1(7.7)\end{array}$ & $\begin{array}{l}29(55.8) \\
29(76.3) \\
25(83.3) \\
12(92.3)\end{array}$ & 7.650 & 0.241 & 0.006 \\
\hline $\begin{array}{l}\text { CD68 } \\
\text { Negative } \\
\text { Positive }\end{array}$ & $\begin{array}{l}59 \\
74\end{array}$ & $\begin{array}{l}19(32.2) \\
19(25.7)\end{array}$ & $\begin{array}{l}40(67.8) \\
55(74.3)\end{array}$ & 0.330 & 0.048 & 0.566 \\
\hline $\begin{array}{l}\text { LC3A } \\
\text { Negative } \\
\text { Positive }\end{array}$ & $\begin{array}{l}66 \\
67\end{array}$ & $\begin{array}{l}21(31.8) \\
17(25.4)\end{array}$ & $\begin{array}{l}45(68.2) \\
50(74.6)\end{array}$ & 1.080 & 0.085 & 0.299 \\
\hline
\end{tabular}

than LNCaP cells. As a result, stemness-related proteins such as LSD1, SOX2, LGR5, and CD44 were co-upregulated with LETM1 in DU145 and PC3 cells but not in LNCaP cells (Figure 2A) (all $P<0.01$ ). Furthermore, LETM1-positive cell population markedly overlapped with the LSD1-positive cell population in PC3 and DU145 cells (Figure 2B and C), and LETM1/LSD1 co-localized in the same PCa tissues (Figure 2D). The expression of LETM1 and LSD1, SOX2, and CD44 in PCa tissue serial sections are shown in Figure 2D. To further verify the relationship between LETM1 and stemness-related proteins, we blocked LETM1 expression using LETM1-specific esiRNA in PCa cells. Knocking down LETM1 expression dramatically decreased the expression of cancer stemness-related proteins such as LSD1, SOX2, and CD44 in PCa cells (Figure 2E and F). Tumor spheroid formation assays showed that in LETM1-silenced PC3 and DU145 cells, tumor spheroid sizes at 1, 7, and 14 days were lower than those in the control group (Figure 2G). These results indicate that LETM1 activation regulates plasticity in PCa.

\section{LETMI Expression Correlates with Cancer Epithelial Cell EMT-Like Changes in PCa}

To investigate the correlation between LETM1 and EMT, protein expression levels of molecular markers including E-cadherin, vimentin, and Snail were analyzed in PCa cells and tissue serial sections through Western blotting and IHC staining. Our results confirmed that expression of LETM1, Snail, and vimentin was higher in poorly differentiated DU145 cells than in more differentiated LNCaP cells, and E-cadherin was down-regulated in DU145 cells (Figure 3A). LETM1 expression was significantly correlated with levels of Snail $(P=0.029)$ and vimentin $(P=0.025)$ in PCa tissues (Figure 3B and Table 2). Moreover, LETM1 knockdown in $\mathrm{PCa}$ cells resulted in significantly higher E-cadherin (PC3: $P<$ 0.01; DU145: $P<0.001)$ expression and lower Snail (PC3: $P<0.001$; DU145: $P<0.01$ ) and vimentin (all $P<0.01$ ) expression than those in the control group (Figure $3 \mathrm{C}$ and $\mathrm{D}$ ).

To further confirm the effects of LETM1 expression on cell migration and invasion of PCa cells, a transwell assay was performed. Our results showed that silencing LETM1 expression dramatically inhibited PC3 (Figure 3E and F) and DU145 (Figure $3 \mathrm{G}$ and $\mathrm{H}$ ) cell migration and invasion. Collectively, our data indicate that LETM1 contributes to metastatic progression of cancer cells by promoting EMT in PCa.

\section{LETMI Is Associated with Cancer Cell Proliferation in $\mathrm{PCa}$}

To investigate the function of LETM1 in the PCa cell cycle, we performed flow cytometry analysis on LETM1-silenced cells. Knockdown of LETM1 resulted in higher G0/G1phase population and lower S-phase subpopulation in PC3 (Figure 4A) and DU145 (Figure 4B) cells than in the controls, but no significant changes were observed in the G2/ M-phase subpopulations. To determine the association of LETM1 with the expression of cell cycle regulator genes (p16, p21, p27, cyclin B1, cyclin D1, and CDK4), we conducted IHC analysis of PCa tissues (Figure 4C). Our results showed that LETM1 expression was positively correlated with the expression of cell cycle regulators such as cyclin D1 $(P<0.001)$ and cyclin B1 $(P<0.001)$ (Table 3). After blocking LETM1 expression with LETM1-specific esiRNA, a dramatic decrease in cyclin D1 and cyclin B1 expression was observed in PC3 and DU145 cells (Figure 4D and E). 
A

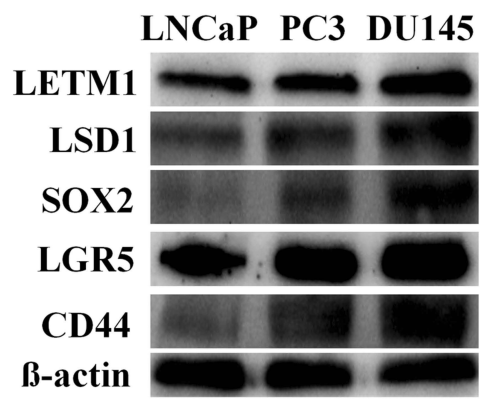

B

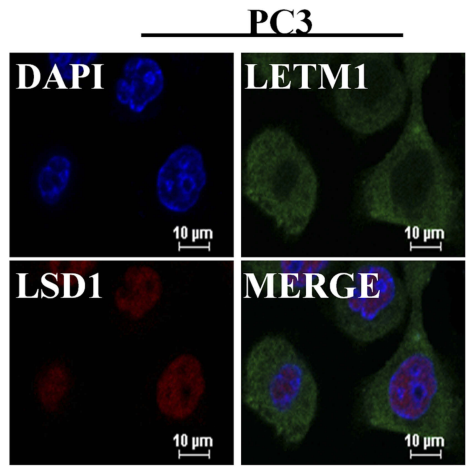

E

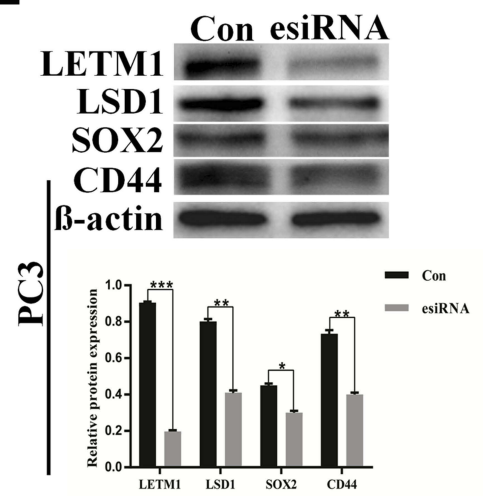

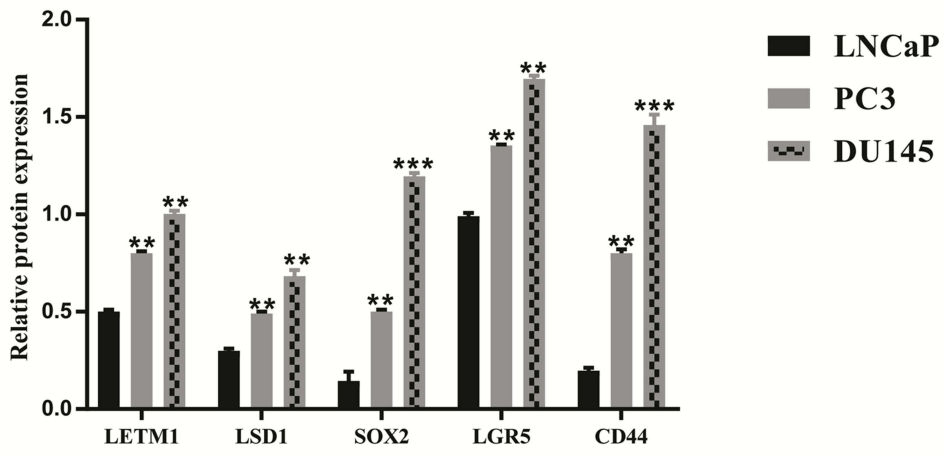

C

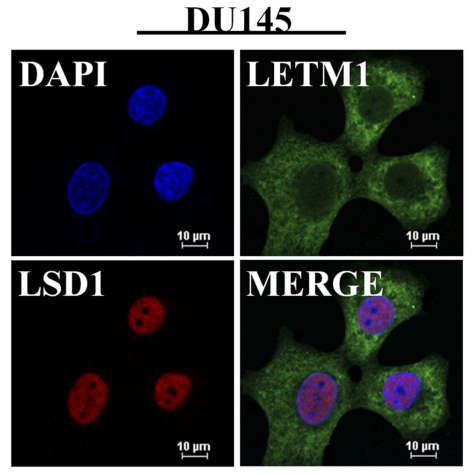

D

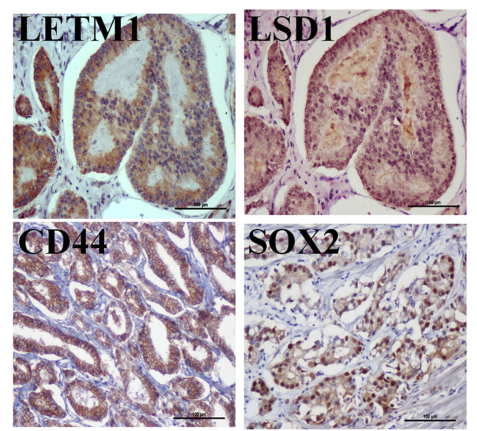

F

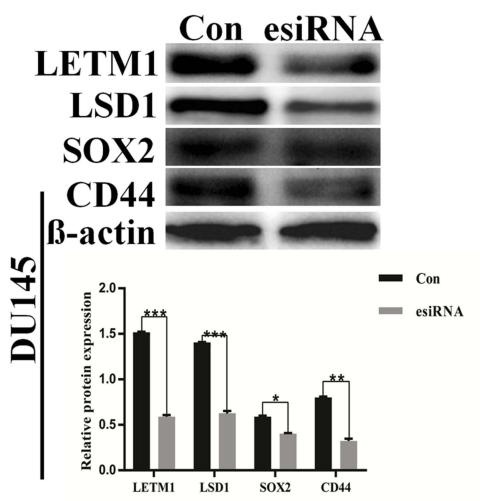

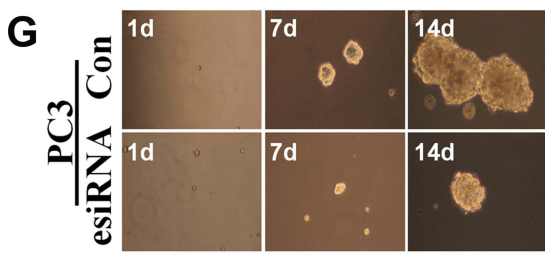

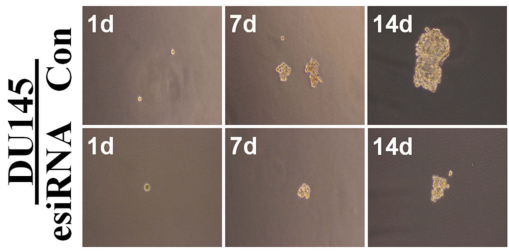

Figure 2 LETMI promotes prostate cancer (PCa) stem cell-like properties. (A) Western blot analysis for the protein levels of LETMI, LSDI, SOX2, LGR5, and CD44 in PCa cells. $\beta$-actin was used as a loading control. (B) and (C) Immunofluorescence staining for LETMI and LSDI in PC3 and DUI45 cells (original magnification 600×). Blue color corresponds to DAPI staining; green to LETMI; red to LSDI; double labeling to merge. (D) Immunohistochemical staining for LETMI, LSDI, SOX2, and CD44 in the PCa tissue (original magnification 200x). Protein expression of LETMI, LSDI, SOX2, and CD44 after LETMI knockdown compared with control in PC3 (E) and DUI45 (F) cells. (G) Sphere-formation assay of PC3 and DUI45 cells with LETMI-knockdown. $* P<0.05$, $* * P<0.01$, $* * * P<0.001$ versus control.

Data indicate that LETM1 regulates cell cycle molecules and promotes proliferation in PCa cells.

\section{Inhibiting PI3K/Akt Signaling Decreases the Expression of LETMI in PCa Cells}

To investigate whether $\mathrm{PI} \mathrm{K} / \mathrm{Akt}$ signaling was responsible for LETM1-mediated PCa progression, we blocked PI3K signaling using LY294002 in PCa cells. Our results showed that $20 \mu \mathrm{M}$ LY294002 (a PI3K inhibitor) significantly inhibited LETM1, pPI3K-p85, and pAkt (Thr308, Ser473) expression in both PC3 (Figure 5A) and DU145 (Figure 5B) cells. In addition, IHC studies showed that LETM1 expression was significantly associated with the expression of pPI3K-p85 $(P<0.001)$ and pAkt-Thr308 $(P<0.001)$ in $\mathrm{PCa}$ tissues (Figure 5C and Table 4). These results indicate that the LETM1 gene is downstream of PI3K/Akt signaling and that PI3K signaling regulates LETM1 expression. 
A

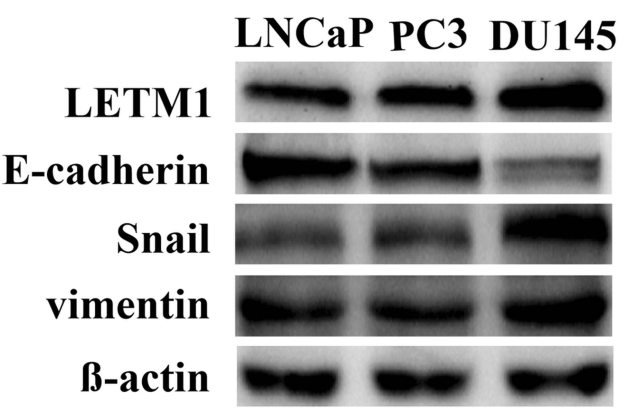

C

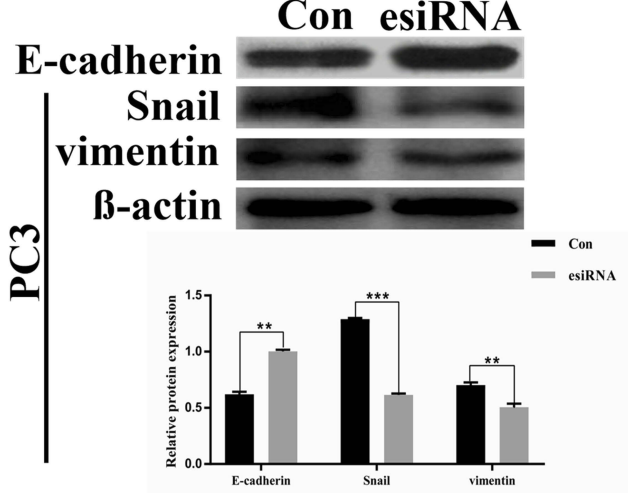

E

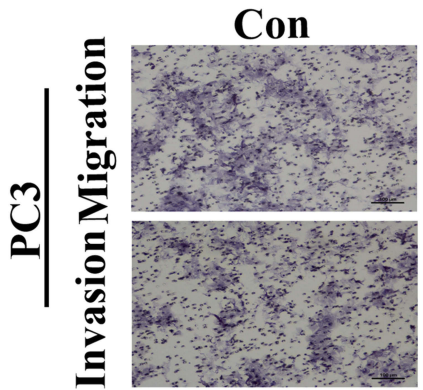

G

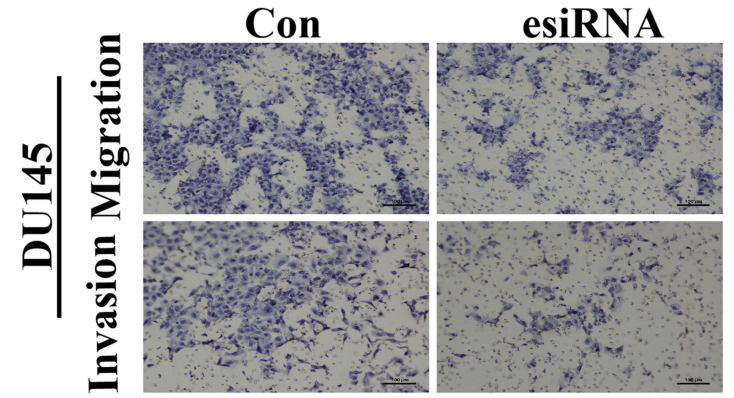

B

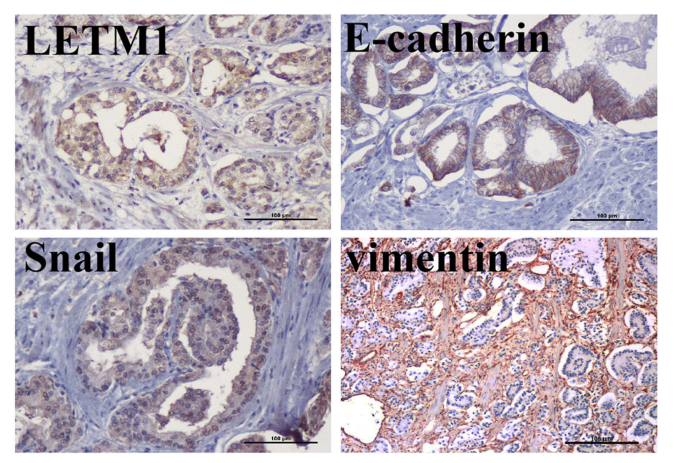

D

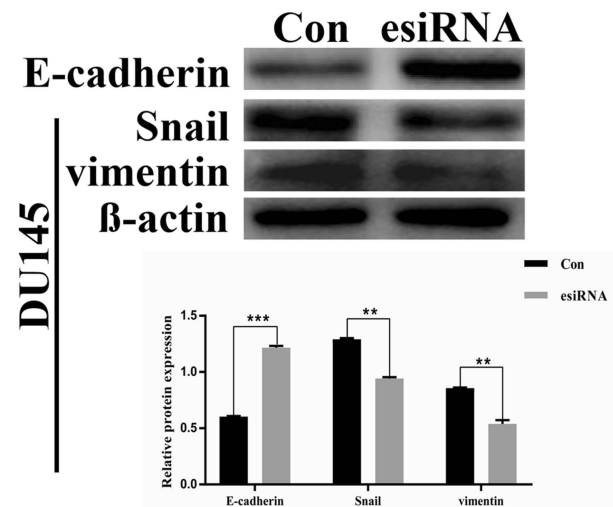

F

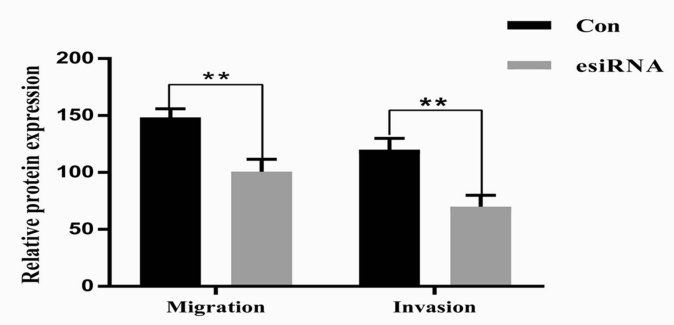

H

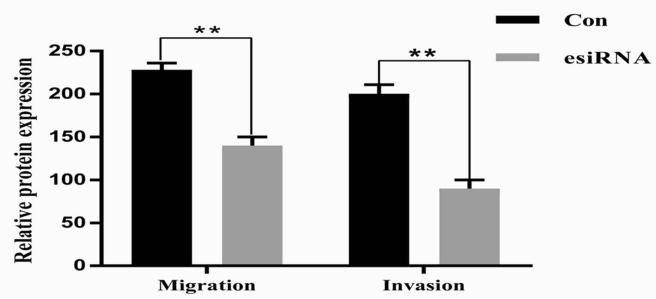

Figure 3 LETMI expression correlates with cancer epithelial cells epithelial-mesenchymal transition (EMT) in prostate cancer (PCa). (A) Western blotting analysis for the protein expression of LETMI, E-cadherin, Snail, and vimentin in PCa cell lines. $\beta$-actin was used as a loading control. (B) Tissue microarray immunohistochemistry staining of PCa for LETMI, and EMT markers E-cadherin, Snail, and vimentin (original magnification 200x). (C) and (D) Effects of silencing LETMI in PC3 and DUI45 cells on E-cadherin, Snail, and vimentin levels. (E-H) PC3 and DUI45 cells' migration and invasion ability was investigated by transwell and Matrigel invasion assays after LETMI knockdown. $* * P<0.01, * * * P<0.001$ versus control.

\section{Discussion}

LETM1 has many diverse functions including calcium or potassium/proton antiport, maintaining mitochondrial morphology, and facilitating mitochondrial translation. ${ }^{17}$ The expression level of LETM1 has been correlated with various human diseases, including cancer. ${ }^{17}$ Recent studies 
Table 2 The Association Between Protein Expression of LETMI and the Factors of EMT in Prostate Cancer

\begin{tabular}{|c|c|c|c|c|c|c|}
\hline Variable & $n$ & $\begin{array}{l}\text { LETMI(-) } \\
\text { n(\%) }\end{array}$ & $\begin{array}{l}\text { LETMI(+) } \\
\text { n(\%) }\end{array}$ & $\chi^{2}$ & $\mathbf{R}$ & $\mathbf{P}$ \\
\hline $\begin{array}{c}\text { E-cadherin } \\
\text { Negative } \\
\text { Positive }\end{array}$ & $\begin{array}{l}34 \\
99\end{array}$ & $\begin{array}{l}8(23.5) \\
30(30.3)\end{array}$ & $\begin{array}{l}26(76.5) \\
69(69.7)\end{array}$ & 0.933 & 0.079 & 0.334 \\
\hline $\begin{array}{l}\text { Snail } \\
\text { Negative } \\
\text { Positive }\end{array}$ & $\begin{array}{l}109 \\
24\end{array}$ & $\begin{array}{l}35(32.1) \\
3(12.5)\end{array}$ & $\begin{array}{l}74(67.9) \\
21(87.5)\end{array}$ & 4.753 & 0.176 & 0.029 \\
\hline $\begin{array}{l}\text { Vimentin } \\
\text { Negative } \\
\text { Positive }\end{array}$ & $\begin{array}{l}39 \\
94\end{array}$ & $\begin{array}{l}16(41.0) \\
22(23.4)\end{array}$ & $\begin{array}{l}23(59.0) \\
72(76.6)\end{array}$ & 5.054 & 0.184 & 0.025 \\
\hline
\end{tabular}

have shown that LETM1 regulates tumorigenesis, tumor progression, and cancer stemness. ${ }^{20,24}$ However, to our knowledge, this is the first study that investigated the relationship between LETM1 expression and cancer cell stemness and EMT-related proteins in $\mathrm{PCa}$ and clarified the significance of LETM1 expression in PCa tissues.

Recent studies have shown that high LETM1 expression is associated with poor prognosis and clinicopathological parameters of various human cancers. ${ }^{20-24}$ In spite of the difference in organs and cancer types, our findings are highly consistent with previous studies in which LETM1 expression was significantly higher in $\mathrm{PCa}$ than in $\mathrm{BPH}$ tissue. Moreover, the level of LETM1 expression was significantly associated with advanced grade, $\mathrm{pT}$, and clinical stages. Subsequently, survival analysis showed that LETM1 overexpression was associated with poor PCa prognosis. In addition, various studies have shown that
A

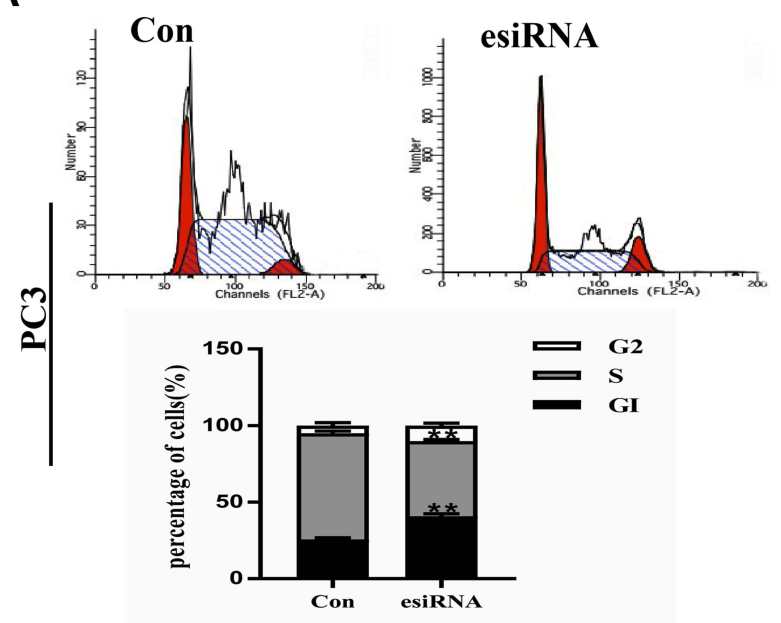

B

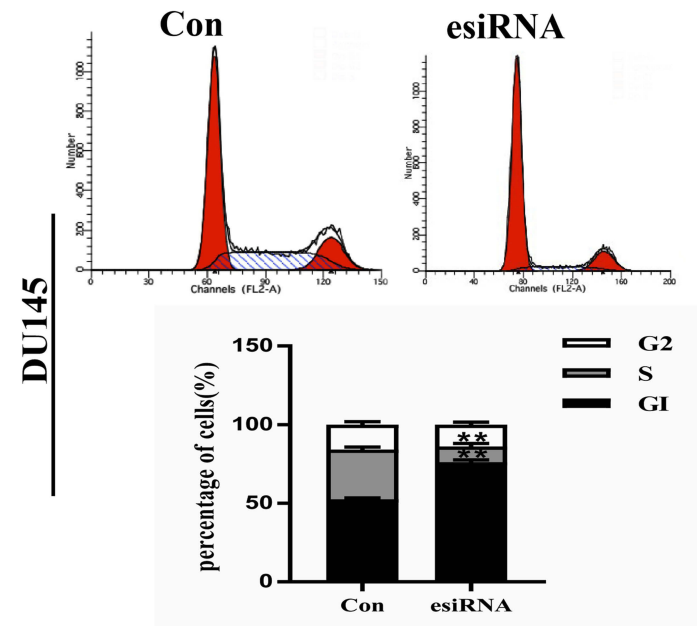

$\mathbf{E}$

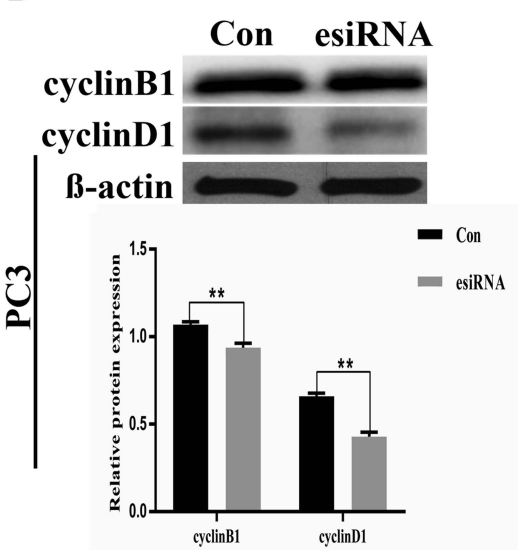

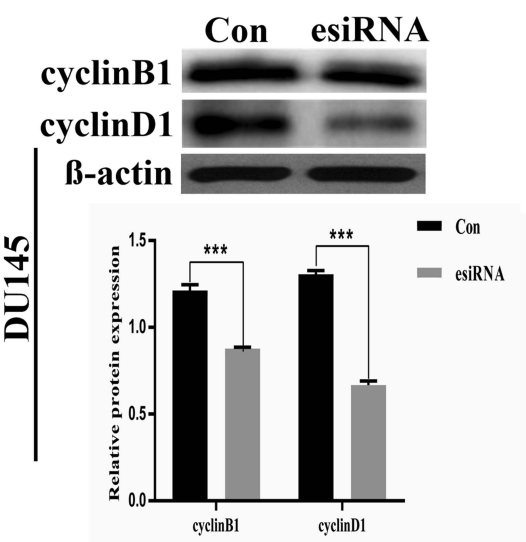

Figure 4 LETMI positively regulates cell proliferation of PCa cells. Representative histograms of the cell cycle distribution in PC3 (A) and DUI45 (B) cells after being transfected with LETMI esiRNA were compared with the control using flow cytometry. The bar graph represents relative cell populations in different cell cycle phases such as G0/GI, S, and G2/M. (C) Immunohistochemical staining of cell cycle genes including pl6, p2I, p27, cyclin DI, cyclin BI, and CDK4 in PCa tissues (original magnification 200x). Protein expression of cyclin DI and cyclin BI after LETMI knockdown compared with control in PC3 (D) and DUI45 (E) cells. **P < $0.0 \mathrm{I}$, $* * * P<0.00 \mathrm{I}$ versus control. 
Table 3 Correlation of LETMI Expression with Cell Cycle Genes Expression in Prostate Cancer

\begin{tabular}{|c|c|c|c|c|c|c|}
\hline Variable & $\mathrm{n}$ & $\begin{array}{l}\text { LETMI } \\
\text { (-) n(\%) }\end{array}$ & $\begin{array}{l}\text { LETMI } \\
(+) n(\%)\end{array}$ & $\chi^{2}$ & $\mathbf{R}$ & $\mathbf{P}$ \\
\hline $\begin{array}{l}\text { Pl6 } \\
\text { Negative } \\
\text { Positive }\end{array}$ & $\begin{array}{l}13 \\
120\end{array}$ & $\begin{array}{l}6(46.2) \\
32(26.7)\end{array}$ & $\begin{array}{l}7(53.8) \\
88(73.3)\end{array}$ & 1.943 & 0.117 & 0.163 \\
\hline $\begin{array}{l}\text { P2l } \\
\text { Negative } \\
\text { Positive }\end{array}$ & $\begin{array}{l}48 \\
85\end{array}$ & $\begin{array}{l}14(29.2) \\
24(28.2)\end{array}$ & $\begin{array}{l}34(70.8) \\
61(71.8)\end{array}$ & 0.001 & 0.003 & 0.973 \\
\hline $\begin{array}{l}\text { P27 } \\
\text { Negative } \\
\text { Positive }\end{array}$ & $\begin{array}{l}8 \\
125\end{array}$ & $\begin{array}{l}2(25.0) \\
36(28.8)\end{array}$ & $\begin{array}{l}6(75.0) \\
89(71.2)\end{array}$ & 0.033 & 0.015 & 0.857 \\
\hline $\begin{array}{c}\text { cyclinDI } \\
\text { Negative } \\
\text { Positive }\end{array}$ & $\begin{array}{l}31 \\
102\end{array}$ & $\begin{array}{l}17(54.8) \\
21(20.6)\end{array}$ & $\begin{array}{l}\mid 4(45.2) \\
81(79.4)\end{array}$ & 17.803 & 0.355 & $<0.001$ \\
\hline $\begin{array}{c}\text { cyclinBI } \\
\text { Negative } \\
\text { Positive }\end{array}$ & $\begin{array}{l}80 \\
53\end{array}$ & $\begin{array}{l}33(41.3) \\
5(9.4)\end{array}$ & $\begin{array}{l}47(58.7) \\
48(90.6)\end{array}$ & 23.356 & 0.400 & $<0.001$ \\
\hline $\begin{array}{l}\text { CDK4 } \\
\text { Negative } \\
\text { Positive }\end{array}$ & $\begin{array}{l}100 \\
33\end{array}$ & $\begin{array}{l}29(29.0) \\
9(27.3)\end{array}$ & $\begin{array}{l}71(71.0) \\
24(72.7)\end{array}$ & 0.048 & 0.019 & 0.826 \\
\hline
\end{tabular}

angiogenesis is crucial for the prognosis, metastasis, and progression of cancer. ${ }^{4,27}$ We found that the MVD was significantly higher in the LETM1-positive group than in the negative group. We speculate that LETM1 plays an important role in tumor initiation and cancer progression and indicates poor $\mathrm{PCa}$ prognosis.

PCa cells express several stem cell biomarkers, such as LSD1, SOX2, CD44, and CD133. ${ }^{28-32}$ LSD1 and its inhibitor have been reported to target CSC markers in several cancers. ${ }^{33,34}$ Sehrawat et al showed that LSD1 promotes PCa cell survival by activating gene networks that regulate the stem cell phenotype. ${ }^{35} \mathrm{SOX} 2$ is a fundamental regulator of stem cell survival and pluripotency that promotes highly aggressive tumor phenotypes. CD44, a cell-surface glycoprotein, has been suggested to be a potential biomarker of prostate stem cells. ${ }^{28}$ Our previous study showed that LETM1 may serve as a novel cancer stemness gene for the prognostic evaluation of CRA and ESCC. ${ }^{20,24}$ In this study, stemness-related proteins were found to be co-upregulated with LETM1 in PCa cells. Furthermore, LETM1 knockdown significantly downregulated CD44, SOX2, and LSD1 expression and the clonogenic ability of PCa cells. These results indicate that LETM1 may play an important role in promoting stemness properties in PCa cells, thereby increasing tumor progression, including tumor relapse and chemoresistance.

Several studies have confirmed that EMT-inducing factors promote EMT and confer CSC-like properties. ${ }^{13,36,37}$ Interrupting or reversing EMT inhibits the invasion and migration of laryngeal cancer cells. ${ }^{38} \mathrm{Xu}$ et al showed that knocking down LETM1 markedly decreases the migration and invasion of renal cell carcinoma cells. ${ }^{39}$ In the present study, LETM1 expression was correlated with EMT-related genes in PCa tissues. In addition, knocking down LETM1 upregulated the expression of the epithelial cell marker E-cadherin while down-regulating the expression of mesenchymal and transcription factor markers vimentin and Snail in PCa cells. LETM1 knockdown down-regulated the migration and invasiveness of the PCa cells. This finding suggested that LETM1 might be involved in PCa cell invasion and migration via activation of the EMT.
A

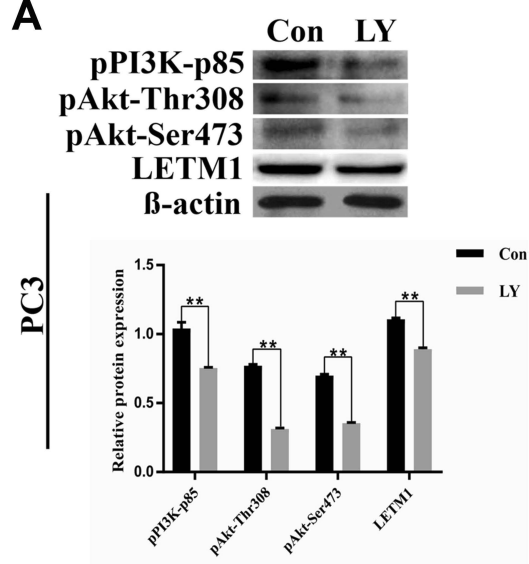

B

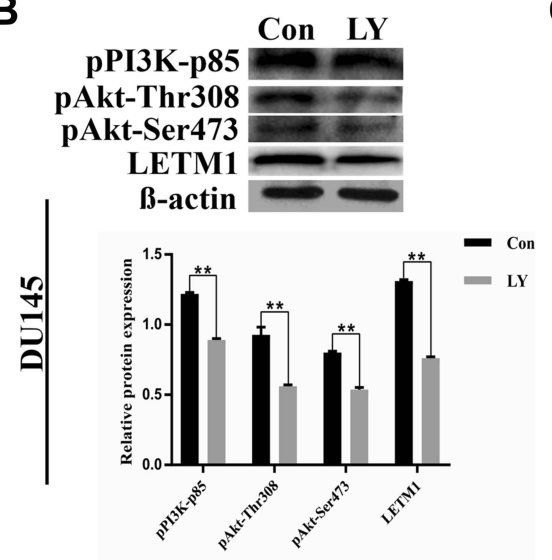

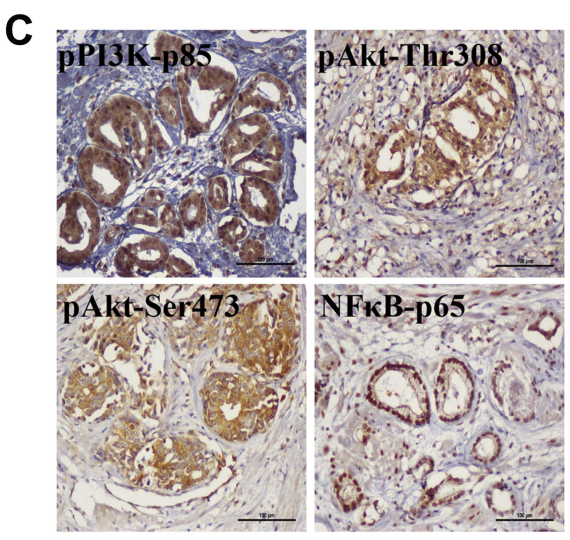

Figure 5 LETMI increases PCa tumorigenesis through the PI3K/Akt signaling pathway. (A) and (B) Western blotting analysis of pPI3K-p85, pAkt-Thr308, pAkt-Ser473, and LETMI after treatment with the PI3K inhibitor LY294002 in PC3 and DUI45 cells. (C) Immunohistochemical staining of pPI3K-p85, pAkt-Thr308, pAkt-Ser473, and NFKB-p65 in PCa tissues (original magnification 200x). **P $<0.01$ versus control. 
Table 4 The Correlation of LETMI Expression with PI3K/Akt/ NF-Kb Signaling Genes Expression in Prostate Cancer

\begin{tabular}{|c|c|c|c|c|c|c|}
\hline Variable & $\mathrm{n}$ & $\begin{array}{l}\text { LETMI } \\
(-) n \\
(\%)\end{array}$ & $\begin{array}{l}\text { LETMI } \\
(+) n \\
(\%)\end{array}$ & $\chi^{2}$ & $\mathbf{R}$ & $\mathbf{P}$ \\
\hline $\begin{array}{c}\text { pPI3K-p85 } \\
\text { Negative } \\
\text { Positive }\end{array}$ & $\begin{array}{l}71 \\
62\end{array}$ & $\begin{array}{l}34(47.9) \\
4(6.45)\end{array}$ & $\begin{array}{l}37(52.1) \\
58(93.5)\end{array}$ & 35.784 & 0.480 & $<0.001$ \\
\hline $\begin{array}{l}\text { PAkt-Thr308 } \\
\text { Negative } \\
\text { Positive }\end{array}$ & $\begin{array}{l}19 \\
114\end{array}$ & $\begin{array}{l}14(73.7) \\
24(21.1)\end{array}$ & $\begin{array}{l}5(26.3) \\
90(78.9)\end{array}$ & 28.388 & 0.457 & $<0.001$ \\
\hline $\begin{array}{l}\text { pAkt-Ser473 } \\
\text { Negative } \\
\text { Positive }\end{array}$ & $\begin{array}{l}28 \\
105\end{array}$ & $\begin{array}{l}6(21.4) \\
32(30.5)\end{array}$ & $\begin{array}{l}22(78.6) \\
73(69.5)\end{array}$ & 1.104 & 0.090 & 0.293 \\
\hline $\begin{array}{c}\text { NFkB-p65 } \\
\text { Negative } \\
\text { Positive }\end{array}$ & $\begin{array}{l}49 \\
84\end{array}$ & $\begin{array}{l}12(24.5) \\
26(31.0)\end{array}$ & $\begin{array}{l}37(75.5) \\
58(69.0)\end{array}$ & 1.225 & 0.092 & 0.268 \\
\hline
\end{tabular}

Cell cycle progression promotes cell proliferation, which in turn leads to clonal expansion of cells during tumor development. ${ }^{40}$ Cyclin D1 is an essential protein in the $\mathrm{G}_{1}$-phase of tumor cells and is highly expressed in actively proliferating non-small cell lung cancer cells. ${ }^{41}$ Cyclin B1, a crucial cell cycle checkpoint protein, promotes mitosis, and the overexpression of cyclin B1 may contribute to uncontrolled cell proliferation. ${ }^{42,43}$ In the present study, overexpression of LETM1 was associated with high expression of cyclin B1 and cyclin D1 in PCa tissues. Furthermore, LETM1 knockdown led to decreased S-phase subpopulations and increased $\mathrm{G}_{0} / \mathrm{G}_{1}$-phase subpopulations in $\mathrm{PCa}$ cells. Our findings are consistent with those of a recent study in which silencing LETM1 expression resulted in HeLa cell cycle arrest and influenced autophagy. ${ }^{16}$ Further, knocking down LETM1 markedly inhibits bladder cancer cell proliferation. ${ }^{22}$ This suggests that the expression of LETM1 leads to unrestrained PCa cell proliferation.

Recent studies have shown that the CSC-like phenotype is associated with activation of the PI3K/Akt/mTOR pathway in prostate cancer. $^{44,45}$ By inhibiting the C-terminal modulator protein, LETM1 promotes activation of $\mathrm{Akt} / \mathrm{PKB},{ }^{46}$ and overexpression of LETM1 may increase the activation of Akt in thyroid cancer cells. ${ }^{23}$ In the present study, we found a significant positive correlation between the expression levels of LETM1 and pPI3K/pAkt. Moreover, treatment with the PI3K-specific inhibitor LY294002 significantly down-regulated LETM1 expression in $\mathrm{PCa}$ cells. These results indicate that PI3K signaling is upstream of LETM1 signaling and regulates the stemness of PCa. Nevertheless, further studies are required to elucidate the specific mechanism.

\section{Conclusion}

In conclusion, LETM1 plays a key role in PCa progression by inducing EMT-like changes and increasing the proliferation capacity of cancer cells. Moreover, the PI3K/Akt pathway plays an essential role in the up-regulation of LETM1. Thus, LETM1 has the potential for being used as a therapeutic target and prognostic biomarker for PCa.

\section{Author Contributions}

All authors contributed toward data analysis, drafting and revising the paper, gave final approval of the version to be published and agree to be accountable for all aspects of the work.

\section{Funding}

This work was supported by grants from the National Natural Science Funds of China (81760531) and Jilin Provincial Education Department Project (JJKH201 91138KJ).

\section{Disclosure}

The authors report no conflicts of interest in this work.

\section{References}

1. Torre LA, Bray F, Siegel RL, et al. Global cancer statistics, 2012. $C A$ Cancer J Clin. 2015;65(2):87-108. doi:10.3322/caac.21262

2. Siegel RL, Miller KD, Jemal A. Cancer statistics, 2017. CA Cancer J Clin. 2017;67(1):7-30. doi:10.3322/caac.21387

3. Huang S, Wa Q, Pan J, et al. Transcriptional downregulation of miR$133 \mathrm{~b}$ by REST promotes prostate cancer metastasis to bone via activating TGF- $\beta$ signaling. Cell Death Dis. 2018;9(7):779-793. doi:10.1038/s41419-018-0807-3

4. Ni WD, Yang ZT, Cui CA, Cui Y, Fang LY, Xuan YH. Tenascin-C is a potential cancer-associated fibroblasts marker and predicts poor prognosis in prostate cancer. Biochem Biophys Res Commun. 2017;486(3):607-612. doi:10.1016/j.bbrc.2017.03.021

5. Qin Y, Dey A, Purayil HT, Daaka Y. Maintenance of androgen receptor inactivation by S-nitrosylation. Cancer Res. 2013;73 (22):6690-6699. doi:10.1158/0008-5472.CAN-13-1042

6. Clarke MF, Fuller M. Stem cells and cancer: two faces of eve. Cell. 2006;124(6):1111-1115. doi:10.1016/j.cell.2006.03.011

7. Dalerba P, Clarke MF. Cancer stem cells and tumor metastasis: first steps into uncharted territory. Cell Stem Cell. 2007;1(3):241-242. doi:10.1016/j.stem.2007.08.012

8. Vermeulen L, De Sousa E Melo F, et al. Wnt activity defnes colon cancer stem cells and is regulated by the microenvironment. Elife. 2010;12(5):468-476.

9. Steffensen KD, Alvero AB, Yang Y, et al. Prevalence of epithelial ovarian cancer stem cells correlates with recurrence in early-stage ovarian cancer. J Oncol. 2011;2011:620523-620534. doi:10.1155/ $2011 / 620523$ 
10. Huang J, Li H, Ren G. Epithelial-mesenchymal transition and drug resistance in breast cancer (Review). Int $J$ Oncol. 2015;47 (3):840-848. doi:10.3892/ijo.2015.3084

11. Li J, Gong X, Jiang R, et al. Fisetin inhibited growth and metastasis of triple-negative breast cancer by reversing epithelial-tomesenchymal transition via PTEN/Akt/GSK3 $\beta$ signal pathway. Front Pharmacol. 2018;9:772-785. doi:10.3389/fphar.2018.00772

12. Mani SA, Guo W, Liao MJ, et al. DNMT1 regulates epithelial-mesenchymal transition and cancer stem cells, which promotes prostate cancer metastasis. Neoplasia. 2016;18(9):553-566. doi:10.1016/j.neo.2016.07.007

13. Mani SA, Guo W, Liao MJ, et al. The epithelial-mesenchymal transition generates cells with properties of stem cells. Cell. 2008;133 (4):704-715. doi:10.1016/j.cell.2008.03.027

14. Shibue T, Weinberg RA. EMT, CSCs, and drug resistance: the mechanistic link and clinical implications. Nat Rev Clin Oncol. 2017;14(10):611-629. doi:10.1038/nrclinonc.2017.44

15. Jiang D, Zhao L, Clapham DE. Genome-wide RNAi screen identifies Letm 1 as a mitochondrial $\mathrm{Ca}^{2+} / \mathrm{H}^{+}$antiporter. Science. 2009;326 (5949):144-147. doi:10.1126/science.1175145

16. Doonan PJ, Chandramoorthy HC, Hoffman NE, et al. LETM1dependent mitochondrial $\mathrm{Ca}^{2+}$ flux modulates cellular bioenergetics and proliferation. FASEB J. 2014;28(11):4936-4949. doi:10.1096/ fsb2.v28.11

17. Piao L, Li Y, Kim SJ, et al. Association of LETM1 and MRPL36 contributes to the regulation of mitochondrial ATP production and necrotic cell death. Cancer Res. 2009;69(8):3397-3404. doi:10.1158/ 0008-5472.CAN-08-3235

18. Tan DQ, Suda T. Reactive oxygen species and mitochondrial homeostasis as regulators of stem cell fate and function. Antioxid Redox Signal. 2018;29(2):149-168. doi:10.1089/ars.2017.7273

19. Khacho M, Clark A, Svoboda DS, et al. Mitochondrial dynamics impacts stem cell identity and fate decisions by regulating a nuclear transcriptional program. Cell Stem Cell. 2016;19(2):232-247. doi:10.1016/j.stem.2016.04.015

20. Piao L, Feng Y, Yang Z, et al. LETM1 is a potential cancer stem-like cell marker and predicts poor prognosis in colorectal adenocarcinoma. Pathol Res Pract. 2019;5:152437. doi:10.1016/j. prp.2019.152437

21. Li N, Zheng Y, Xuan C, et al. LETM1 overexpression is correlated with the clinical features and survival outcome of breast cancer Int J Clin Exp Pathol. 2015;8(10):12893-12900.

22. Huang B, Zhang J, Zhang X, et al. Suppression of LETM1 by siRNA inhibits cell proliferation and invasion of bladder cancer cells. Oncol Rep. 2017;38(5):2935-2940. doi:10.3892/or.2017.5959

23. Lee J, Lee WK, Seol MY, et al. Coupling of LETM1 up-regulation with oxidative phosphorylation and platelet-derived growth factor receptor signaling via YAP1 transactivation. Oncotarget. 2016;7 (41):66728-66739. doi:10.18632/oncotarget.11456

24. Yang Z, Ni W, Cui C, et al. Identification of LETM1 as a marker of cancer stem-like cells and predictor of poor prognosis in esophageal squamous cell carcinoma. Hum Pathol. 2018;8177(18):30258-30262.

25. Yang Z, Yeo S, Yin Y, et al. Tenascin-C, a prognostic determinant of esophageal squamous cell carcinoma. PLoS One. 2016;11(1): e0145807. doi:10.1371/journal.pone.0145807

26. Yang Z, Zhang C, Qi W, et al. GLI1 promotes cancer stemness through intracellular signaling pathway $\mathrm{PI} 3 \mathrm{~K} / \mathrm{Akt} / \mathrm{NF} \kappa \mathrm{B}$ in colorectal adenocarcinoma. Exp Cell Res. 2018;373(1-2):145-154. doi:10.1016/j.yexcr.2018.10.006

27. Yuri P, Hendri AZ, Danarto R. Association between tumor-associated macrophages and microvessel density on prostate cancer progression. Prostate Int. 2015;3(3):93-98. doi:10.1158/0008-5472.CAN-11-0896

28. Patrawala L, Calhoun T, Schneider-broussard R, et al. Highly purifified CD44p prostate cancer cells from xenograft human tumors are enriched in tumorigenic and metastatic progenitor cells. Oncogene. 2006;25(12):1696-1708. doi:10.1038/sj.onc.1209327
29. Ugolkov AV, Eisengart LJ, Luan C, et al. Expression analysis of putative stem cell markers in human benign and malignant prostate. Prostate. 2011;71(1):18-25. doi:10.1002/pros.21217

30. Fong H, Hohenstein KA, Donovan PJ. Regulation of self-renewal and pluripotency by Sox2 in human embryonic stem cells. Stem Cells. 2008;26(8):1931-1938. doi:10.1634/stemcells.2007-1002

31. Kalantari E, Asgari M, Nikpanah S, et al. Co-expression of putative cancer stem cell markers CD44 and CD133 in prostate carcinomas. Pathol Oncol Res. 2017;23(4):793-802. doi:10.1007/s12253-0160169-z

32. Ketscher A, Jilg CA, Willmann D, et al. LSD1 controls metastasis of androgen-independent prostate cancer cells through PXN and LPAR6. Oncogenesis. 2014;3(10):e120.

33. Wang J, Lu F, Ren Q, et al. Novel histone demethylase LSD1 inhibitors selectively target cancer cells with pluripotent stem cell properties. Cancer Res. 2011;71(23):7238-7249. doi:10.1158/00085472.CAN-11-0896

34. Zhang X, Lu F, Wang J, et al. Pluripotent stem cell protein Sox2 confers sensitivity to LSD1 inhibition in cancer cells. Cell Rep. 2013;5(2):445-457.

35. Sehrawat A, Gao L, Wang Y, et al. LSD1 activates a lethal prostate cancer gene network independently of its demethylase function. Proc Natl Acad Sci USA. 2018;115(18):4179-4188. doi:10.1073/ pnas. 1719168115

36. Morel AP, Lièvre M, Thomas $\mathrm{C}$, et al. Generation of breast cancer stem cells through epithelial-mesenchymal transition. PLoS One. 2008;3(8):e2888.

37. Jiang R, Zhang C, Liu G, et al. MicroRNA-126 inhibits proliferation, migration, invasion and EMT in osteosarcoma by targeting ZEB1. J Cell Biochem. 2017;118(11):3765-3774. doi:10.1002/jcb. v118.11

38. Mao W, Sun Y, Zhang H, et al. A combined modality of carboplatin and photodynamic therapy suppresses epithelial-mesenchymal transition and matrix metalloproteinase-2 (MMP-2)/MMP-9 expression in HEp-2 human laryngeal cancer cells via ROS-mediated inhibition of MEK/ERK signalling pathway. Lasers Med Sci. 2016;31 (8):1697-1705. doi:10.1007/s10103-016-2040-6

39. Xu J, Huang B, Saiyang L, et al. Knockdown of LETM1 inhibits proliferation and metastasis of human renal cell carcinoma cells. Oncol Lett. 2018;16(5):6377-6382. doi:10.3892/ol.2018.9449

40. Zhong ZQ, Song MM, He Y, et al. Knockdown of Ezrin by RNA interference reverses malignant behavior of human pancreatic cancer cells in vitro. Asian Pac J Cancer Prev. 2012;13(8):3781-3789. doi:10.7314/APJCP.2012.13.8.3781

41. Chikara S, Lindsey K, Dhillon H, et al. Enterolactone induces G1-phase cell cycle arrest in nonsmall cell lung cancer cells by downregulating cyclins and cyclin-dependent kinases. Nutr Cancer. 2017;69(4):652-662. doi:10.1080/01635581.2017.1296169

42. Zhang X, Cai J, Zheng Z, et al. A novel ER-microtubule-binding protein, ERLIN2, stabilizes Cyclin B1 and regulates cell cycle progression. Cell Discov. 2015;1:15024-15041. doi:10.1038/ celldisc. 2015.24

43. Suzuki T, Urano T, Miki Y, et al. Nuclear cyclin B1 in human breast carcinoma as a potent prognostic factor. Cancer Sci. 2007;98 (5):644-651. doi:10.1111/j.1349-7006.2007.00444.x

44. Jiang L, Wang Z, Liu C, et al. TrkB prometes laryngeal cancer metastasis via activation PI3K/Akt pathway. Oncotarget. 2017;8 (65):108726-108737. doi:10.18632/oncotarget.21711

45. Chang L, Graham $\mathrm{PH}$, Hao J, et al. Acquisition of epithelial-mesenchymal transition and cancer stem cell phenotypes is associated with activation of the PI3K/Akt/mTOR pathway in prostate cancer radioresistance. Cell Death Dis. 2013;4:e875. doi:10.1038/cddis.2013.407

46. Park J, Li Y, Kim SH, et al. New players in high fat diet-induced obesity: LETM1 and CTMP. Metabolism. 2014;63(3):318-327. doi:10.1016/j.metabol.2013.10.012 


\section{Publish your work in this journal}

Cancer Management and Research is an international, peer-reviewed open access journal focusing on cancer research and the optimal use of preventative and integrated treatment interventions to achieve improved outcomes, enhanced survival and quality of life for the cancer patient.
The manuscript management system is completely online and includes a very quick and fair peer-review system, which is all easy to use. Visit http://www.dovepress.com/testimonials.php to read real quotes from published authors.

Submit your manuscript here: https://www.dovepress.com/cancer-management-and-research-journal 